\title{
Percutaneous Endovascular Management of Ascending Aortic Pseudoaneurysm after Heart Transplantation in a Pediatric Patient
}

\author{
Antonio Skrabonja-Crespo ${ }^{1}$, Fernando Chavarri-Velarde ${ }^{1}$, Miguel Pinto-Salinas $^{2}$, and \\ Astrid Tauma-Arrué ${ }^{3}$ \\ ${ }^{1}$ Instituto Nacional Cardiovascular "Carlos Alberto Peschiera Carrillo" \\ ${ }^{2}$ Universidad Nacional Mayor de San Marcos Facultad de Medicina de San Fernando \\ ${ }^{3}$ Universidad Nacional Mayor de San Marcos
}

September 11, 2020

\begin{abstract}
Ascending aortic pseudoaneurysm is a rare complication in heart transplantation. Surgery is the most conventional management, but, in some cases, it is high-risky. We report the case of a ten-year-old child with heart transplantation that developed ascending aortic pseudoaneurysm in the aortic anastomosis successfully treated with two covered stents through endovascular management. To our knowledge, this is the first report about endovascular therapy of an ascending aorta pseudoaneurysm after heart transplantation in a pediatric patient.
\end{abstract}

\section{Introduction}

Ascending aorta pseudoaneurysm (AAP) is a rare and high mortality complication of cardiac surgery $(1,2)$. Some predisposing factors are leakage by cannulation sites, suture lines, aortic grafts anastomosis, and infections (2). The most conventional management is surgery (3). Some authors had proposed alternative options such as grafts, vascular plugs, stents, coil embolization, and thrombin injection (3-5). We report the case of a ten-year-old male who had a pseudoaneurysm of ascending aorta after orthotopic heart transplantation and was treated successfully with endovascular stents placement.

\section{Case Report}

A nine-year-old male with a past medical history of refractory heart failure due to non-ischemic dilated cardiomyopathy underwent to bicaval/unipulmonar technique for orthotopic heart transplantation (HT) after four weeks of waiting time. In the postoperative course, the child presented biventricular failure, acute $1 \mathrm{R}$ cell rejection, and nosocomial pneumonia that were satisfactorily resolved. Therefore, he was discharged with immunosuppressive treatment with prednisone, tacrolimus, and mycophenolate mofetil, 21 days after HT.

Three months later, the child presented with fever, arthritis, dyspnea, and a heart murmur. A blood culture tested positive to methicillin-sensitive Staphylococcus aureus, and he started receiving antibiotic therapy with oxacillin and clindamycin until testing negative during the control. A transthoracic echocardiogram showed no signs of endocarditis. Then, a multi-slice computed tomography (MSCT) evidenced a $16.2 \mathrm{~mm}$ $\mathrm{x} 14.2 \mathrm{~mm}$ pseudoaneurysm in the left side of the aortic anastomosis area (Figure 1). There was a distance of $30 \mathrm{~mm}$ from the neck to the left coronary ostium. In MSCT reconstruction, there was a mass compatible with an AAP in the same location (Figure 2). Through catheter-based aortography (CBA), the AAP was confirmed, measuring $17 \mathrm{~mm} \times 16 \mathrm{~mm}$ (Figure 3A, Supplemental Video 1) with a neck of $6.8 \mathrm{~mm}$ with blood flow, and a diameter of $18 \mathrm{~mm}$ from the ascending aorta. The coronary arteries were not compromised. 
After several discussions among our cardiopediatric team, the child was deemed as a high-risk surgical patient because of his medical background and the location of the AAP. Thereby, the percutaneous endovascular approach of the pseudoaneurysm was indicated. Unfortunately, it could not be done promptly due to logistical failures and the stabilization of infection. Besides, the patient was evaluated periodically by the cardiopediatric department, and no new clinical features were reported. However, a MSCT performed after eight months revealed an increase in the lesion's measures to $20.5 \mathrm{~mm} \times 18.4 \mathrm{~mm}$ without clinical changes or hemodynamic instability. Therefore, the patient was scheduled to perform endovascular treatment.

The patient was admitted to perform the interventional procedure to close the AAP. After the dissection of the left common carotid artery and the puncture of the artery by Seldinger's technique under direct vision, an 8-French sheath was inserted, and a 0.035 " J-guide. Then, a 5-French pigtail catheter was positioned to the side of the AAP, and the findings were confirmed. The J-guide was changed to an Amplatz Super Stiff 0.035", and the access was upgraded to a 14-French sheath. Then, a $39 \mathrm{~mm}$ covered Cheatham Platinum (CP) stent pre-mounted on an $18 \mathrm{~mm} \times 4 \mathrm{~cm} / 9 \mathrm{~mm} \times 3 \mathrm{~cm}$ balloon in balloon (BIB) catheter was advanced to the side of the AAP under CBA guidance. After the manual CBA-controlled insufflation of the inner balloon followed by the 6-atm-controlled insufflation of the outer one, it was evidenced residual blood flow into the AAP and a slight distal displacement of the stent (Figure 3B). Thereby, a second stent with greater length was needed. The first BIB catheter was removed, and a $45 \mathrm{~mm}$ covered CP stent pre-mounted on a $20 \mathrm{~mm} \times 5 \mathrm{~cm} / 10 \mathrm{~mm} \times 4 \mathrm{~cm}$ BIB catheter was advanced toward the location of the first stent under CBA guidance. The balloons were insufflated consecutively with the same technique, followed by a control CBA, which showed the patency of the coronary ostia and absence of perfusion of the AAP (Figure 3C, Supplemental Video 2). Finally, the catheters were removed, and the carotid artery was closed by pursestring suture with $7 / 0$ polypropylene. The patient left the operating room extubated and in spontaneous breathing. Then, he was admitted to 24 -hour routine surveillance in the Intensive Care Unit.

The patient remained hemodynamically stable and had a favorable evolution. He was discharged with an indication of $100 \mathrm{mg}$ daily of acetylsalicylic acid for six months. After a five-month follow-up, the patient was asymptomatic and without complications reported.

\section{Discussion}

This report describes a successful closure of an AAP with endovascular management in a ten-year-old patient. Aortic pseudoaneurysms are rare complications in cardiovascular surgery that occurs in less than $0.5 \%$ of patients $(4,6)$. Similarly, this complication is infrequent concerning HT, and it is rarer among pediatric patients $(7,8)$. This complication has a morbimortality rate between 29 and $46 \%$ (6). Its pathogenesis is based on the weakness of at least one layer of the aorta, and the blood is contained by fibrous tissue or pericardium $(1,9)$. Some predisposing factors are graft infection, trauma, tissue fragility in the anastomosis area, aortic cannulation sites, cardioplegic cardiac puncture, a dissected native aorta, and tissue necrosis due to biological glue $(1,2,10)$.

The clinical features can be dyspnea, hemoptysis, chest pain, respiratory failure, and cardiogenic shock $(4,10,11)$. Although, patients can remain asymptomatic, and pseudoaneurysms are incidental findings of imaging exams $(1,4)$. Usually, small pseudoaneurysms do not cause clinical manifestations, but a periodical follow-up is needed to surveillance the dimensions and to reevaluate possible therapeutic options (1). Likewise, within the reported complications are the pseudoaneurysm rupture, local compression, and erosion of surrounding tissues, sources for infection and thrombus $(2,4,10)$. In this case, the patient was hemodynamically stable, and the only clinical feature was a cardiac murmur. Therefore, the diagnosis was incidental with a MSCT.

The conventional management is the open surgery with the resection of the pseudoaneurysm. Reoperations are associated with extensive bleeding or cerebral air embolism during resternotomy (4). In the literature, most patients with a history of heart transplantation were treated by surgery $(8,12,13)$. However, in highrisk patients, some authors have proposed new alternatives such as using Atrial Septal Defect occluder, vascular plugs, stents, coil embolization, and thrombin injection with favorable outcomes (3-5). Endovascular 
management is less aggressive and associated with less blood loss and shorter procedural durations $(3,4)$.

Additionally, Joyce et al. published a case report of an adult patient with lung-heart transplantation who was treated by an endovascular approach with favorable outcomes (14). Nevertheless, the complications are endoleaks, open conversion, migration of the stents, and myocardial infarctions. Thereby, it is recommendable a close follow-up of these patients $(3,11)$. The patient presented was considered for endovascular management due to his high-risk factors, location of the AAP, non-compromise of the coronary ostia, and previous experience of our cardiopediatric team with similar procedures. Besides, some authors suggest that the landing zone of the stent in the ascending aorta must be at least $2 \mathrm{~cm}$ and aortic diameter less than $40 \mathrm{~mm}$, which was possible to achieve in our patient $(11,15)$.

\section{Conclusion}

To our knowledge, this is the first case that presents the successfully endovascular management of an AAP as a complication of a HT in a pediatric patient.

\section{ORCID iD}

Antonio Skrabonja-Crespo https://orcid.org/0000-0002-5435-2146

Fernando Chavarri-Velarde https://orcid.org/0000-0003-2524-0003

Miguel Pinto-Salinas https://orcid.org/0000-001-5789-3960

Astrid Tauma-Arrué https://orcid.org/0000-0003-2915-2158

\section{Author contributions}

AS and FC were specialists in charge of the patient, designed and proposed the management. MP and AT carried out the data collection. AS, FC, MP, and AT performed the interpretation, critical review of state of the art and the paper, and the article's final approval.

\section{References}

1. Sabri MN, Henry D, Wechsler AS, DiSciascio G, Vetrovec GW. Late complications involving the ascending aorta after cardiac surgery: Recognition and management. Am Heart J. 1991 Jun;121(6):1779-83.

2. Katsumata T, Moorjani N, Vaccari G, Westaby S. Mediastinal false aneurysm after thoracic aortic surgery. Ann Thorac Surg. 2000 Aug;70(2):547-52.

3. Di Marco L, Lovato L, Murana G, Amodio C, Buia F, Di Bartolomeo R, et al. Endovascular repair of ascending aorta pseudoaneurysm. J Vis Surg. 2018 May;4:116-116.

4. Fukunaga N, Koyama T. Outcomes of surgical repairs for thoracic aortic pseudoaneurysms after cardiovascular surgery. J Card Surg. 2016 Aug;31(8):535-40.

5. Weinberger T, Nabauer M, Massberg S, Hausleiter J. Interventional Closure of a Large Pseudoaneurysm of the Ascending Aorta in a Patient after Lung Transplantation. CASE. 2019 Dec;3(6):263-6.

6. Jung T-E, Lee D-H. Surgery for pseudoaneurysm of the ascending aorta under moderate hypothermia. J Cardiothorac Surg [Internet]. 2011 Dec [cited 2020 Feb 4];6(1). Available from: https://cardiothoracicsurgery.biomedcentral.com/articles/10.1186/1749-8090-6-125

7. Vigano' M, Rinaldi M, D’Armini AM, Pederzolli C, Minzioni G, Grande AM. The spectrum of aortic complications after heart transplantation. Ann Thorac Surg. 1999 Jul;68(1):105-11.

8. Kanter KR, Mahle WT, Vincent RN, Berg AM. Aortic Complications After Pediatric Cardiac Transplantation in Patients With a Previous Norwood Reconstruction. Semin Thorac Cardiovasc Surg Pediatr Card Surg Annu. 2011 Jan;14(1):24-8. 
9. Dumont E, Carrier M, Cartier R, Pellerin M, Poirier N, Bouchard D, et al. Repair of aortic false aneurysm using deep hypothermia and circulatory arrest. Ann Thorac Surg. 2004 Jul;78(1):117-20.

10. Fukunaga N, Koyama T, Konishi Y, Murashita T, Yuzaki M, Shomura Y, et al. Reoperation for pseudoaneurysm of the thoracic aorta after cardiovascular surgery. Surg Today. 2014 Jan;44(1):94-9.

11. Roselli EE, Idrees J, Greenberg RK, Johnston DR, Lytle BW. Endovascular stent grafting for ascending aorta repair in high-risk patients. J Thorac Cardiovasc Surg. 2015 Jan;149(1):144-54.

12. Yamane K, Hirose H, Mather PJ, Silvestry SC. Mycotic Pseudoaneurysm of the Ascending Aorta After Heart Transplantation: Case Report. Transplant Proc. 2011 Jun;43(5):2055-8.

13. Behzadnia N, Ahmadi ZH, Mandegar MH, Salehi F, Sharif-Kashani B, Pourabdollah M, et al. Asymptomatic Mycotic Aneurysm of Ascending Aorta After Heart Transplantation: A Case Report. Transplant Proc. 2015 Jan;47(1):213-6.

14. Joyce DL, Singh SK, Mallidi HR, Dake MD. Endovascular Management of Pseudoaneurysm Formation in the Ascending Aorta Following Lung Transplantation. J Endovasc Ther. 2012 Feb;19(1):52-7.

15. Preventza O, Henry MJ, Cheong BYC, Coselli JS. Endovascular Repair of the Ascending Aorta: When and How to Implement the Current Technology. Ann Thorac Surg. 2014 May;97(5):1555-60.

\section{FIGURES:}

Figure 1. Preprocedural MSCT shows the AAP (white arrow) with a size of $16.2 \mathrm{~mm} \times 14.2 \mathrm{~mm}$ and a neck (yellow arrow) adjacent to the left side of aortic anastomosis.

Figure 2. A frontal view of a MSCT reconstruction shows the AAP (white arrow) adjacent to the left side of aortic anastomosis.

Figure 3. Transcarotid closure of the AAP using two Cheatham Platinum stents. A, Preprocedural CBA shows the AAP from the left side of aortic anastomosis. B , CBA after placement of the first covered stent shows the residual blood flow into the APP.C, CBA after placement of the second covered stent without flow into the APP.

\section{SUPPLEMENTARY MATERIAL:}

VIDEO 1. CBA before placement of stents showing the AAP from the aortic anastomosis.

VIDEO 2. CBA after placement of the second covered stent without flow into the APP. 


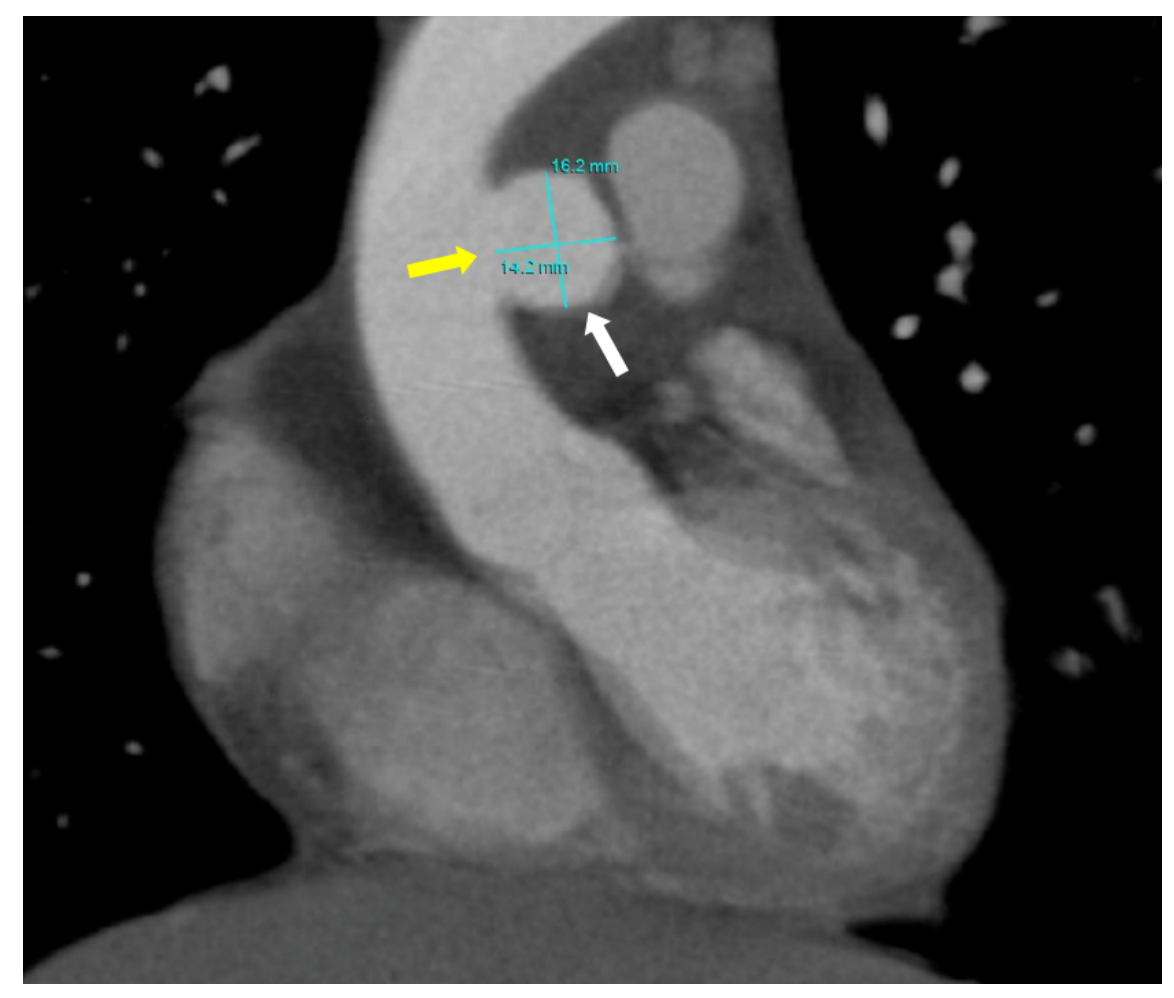



